\title{
Diagnostic Features of Auditory Function in Patients with Arterial Hypertension
}

\author{
Lisotskaya VV*, Merkulova EP, Greben NI and Eremenko UE \\ The Ministry of Health of the Republic of Belarus, State Institution, The Republican Center for Research and Practice in Otolaryngology, The city of Minsk, \\ Republic of Belarus
}

Submission: April 04, 2019; Published: April 17, 2019

*Corresponding author: Lisotskaya VV, The Ministry of Health of the Republic of Belarus, State Institution, The Republican Center for Research and Practice in Otolaryngology, The city of Minsk, Republic of Belarus

\section{Abstract}

Introduction: Hypertension is a risk factor for Sensorineural Hearing Loss. However, the level of central or peripheral lesion has not been established yet. The gold standard for hearing examination - Pure tone audiometry - is an insensible method in this case. What necessitates the search for the most sensitive method for the diagnosis of hearing disorders in patients with Arterial Hypertension.

The object: 20 patients with low-risk primary hypertension with normal hearing threshold and 20 healthy patients studied at Audiology department of the State Institution "The Republican Center for Research and Practice in Otolaryngology", from 2018 to 2019 year.

Aim: To determine the most effective method of diagnostic hearing disorders in patients

with Arterial Hypertension.

Methodology: mathematical statistics, Student t-test, Fisher test. All patients underwent DPOAE, TEOAE, tympanometry and acoustic reflexes, Auditory Brainstem Response, high-frequency audiometry, Word Recognition test, Rapidly Alternating Speech Perception Test, Dichotic Digits Test.

Results: The study involved 40 individuals an equal man $(\mathrm{N}=25)$ and women $(\mathrm{N}=15)$ in the middle age at $38,31 \pm 10$ years $(95 \%$ CI 18 55 years). All patients ( $\mathrm{N}=40$ ) were divided into 2 groups: 1 group - patients with hypertension, 2 group - without hypertension. It was found that patients of the first group complained of a decrease in speech intelligibility $(\mathrm{N}=16)$, difficulty in recognizing speech in polyphony( $\mathrm{N}=14)$, tinnitus( $(\mathrm{N}=12)$, hearing loss $(\mathrm{N}=3)$. Tinnitus was observed only in patients with decreased diastolic pressure «over deep» according to daily blood pressure monitoring. Tympanogram type A was registered in all the patients in two groups $(\mathrm{N}=40)$ with bilateral acoustic reflexes. High-frequency audiometry showed any changes only in $1 / 3$ of the studied first group ( $N=7$ ). No statistically significant difference was observed between the both groups with and without arterial hypertension in either DPOAE or TEOAE. But the arterial hypertension group showed significantly lower results at 1501, $2002 \mathrm{~Hz}$ frequencies by the distortion-product otoacoustic emissions. It was significantly revealed an elongation of the interval III-V $(t \geq 0,95)$ with an increase in the amplitude and an increase in the latency of the wave $V(t \geq 0,93)$ in the group with arterial hypertension. Speech intelligibility was $80 \pm 5 \%(t \geq 0,95)$ with an extremely low percentage of passing digital dichotic tests- $5 \%$ in patients of the first group.

Conclusion: Arterial hypertension is a systemic disease that causes damage to the organ of hearing at the central and peripheral levels. Word Recognition and Dichotic Digits Test should be used for diagnosing hearing impairment in addition to the standard battery tests.

Abbreviations: Central Auditory Processing Disorders (CAPD); Arterial Hypertension (AH); Distortion product otoacoustic emissions (DPOAE); Pure-Tone Audiometry (PTA); Auditory Brainstem Response (ABR)

\section{Introduction}

Due to World Health Organization, hypertension, also known as high or raised blood pressure, is a condition in which the blood vessels have persistently raised pressure. Blood is carried from the heart to all parts of the body in the vessels. Each time the heart beats, it pumps blood into the vessels. Blood pressure is created by the force of blood pushing against the walls of blood vessels (arteries) as it is pumped by the heart. According to office blood pressure in 2015, the global prevalence of hypertension was estimated at 1.13 billion, and in central and eastern Europe more than 150 million [1]. The overall prevalence of arterial hypertension in adults in 2015 is about $30-45 \%, 12$ with a global age-standardized prevalence of $24 \%$ and $20 \%$ among men and women, respectively. In turn, the long term of the disease with arterial hypertension leads to damage of the target organs: brain, kidneys, and heart. This complication can lead to death [24]. Hypertension causes structural changes in the cardiovascular system in general and the circulatory system of the inner ear - induce hemorrhage. This may contribute to progressive sensorineural hearing loss [5]. There are many articles on the relationship between Sensorineural Hearing Loss and Arterial 
Hypertension [6]. Until then, there remains an open question of the predominance of the central or peripheral link of the organ of hearing [7]. However, the genesis of the mechanism of hearing impairment is still not known. This, in turn, necessitates further research on the relationship between increasing pressure and functional congestion of the hearing organ.

\section{Methods}

A prospective chart review was performed for patients who are diagnosed with Arterial Hypertension at "THE REPUBLICAN CENTER FOR RESEARCH AND PRACTICE IN OTOLARYNGOLOGY" of Republic of Belarus for 2018 year. Eligibility criteria includes the age of patients elder than 18 years old, primary arterial hypertension, arterial hypertension 1-2 degree with low risk, absence of hemodynamically significant cerebrovascular, brachiocephalic circulatory disorders. Roll out structural pathology was excluded for all patients: the absence of concomitant pathology of the endocrine, digestive, nervous, immune, musculoskeletal, respiratory, urinary systems, lack of cancer. All patients had no pathology of violations of the circulatory and blood. All studied people with elevated blood pressure underwent a standard battery of tests: DPOAE, TEOAE, tympanometry and acoustic reflexes, auditory brainstem response, pure-tone audiometry, Word Recognition Test, Rapidly Alternating Speech Perception Test, Dichotic Digits Test (AC 40; Interacoustics, Denmark). All patients with arterial hypertension underwent a study of daily blood pressure monitoring. In puretone audiometry, hearing thresholds 500, 1000, 2000, 3000, $4000,6000 \mathrm{~Hz}$ frequencies were received. The pure tone average
(PTA) was determined by calculating the arithmetic mean of amount of the 500,1000, 2000 and $4000 \mathrm{~Hz}$ thresholds. The audiograms could be characterized like a normal line at different thresholds. To assess the subjective feeling, a test was used THI test recommended by Hearing Loss Association of America. Oneway ANOVA and Kruskal-Wallis tests were used for comparing numerical variables. For subgroup analyses, t-Student and Fisher tests and Mann- Whitney U tests were chosen for parametric and nonparametric evaluations, respectively.

\section{Results}

The study involved 40 individuals an equal man $(\mathrm{N}=25)$ and women $(\mathrm{N}=15)$ in the middle age at $38,31 \pm 10$ years $(95 \% \mathrm{CI}$ 18-55 years). The principle of dividing into groups included the presence of hypertension in the individuals studied. All patients $(\mathrm{N}=40)$ were divided into 2 groups: 1 group - patients with arterial hypertension, 2 group - patients without hypertension. It was found that patients of the first group complained of a decrease in speech intelligibility $(\mathrm{N}=16)$, difficulty in recognizing speech in polyphony $(\mathrm{N}=14)$, tinnitus $(\mathrm{N}=12)$, hearing loss $(\mathrm{N}=3)$. Analysis of the nature of the complaints of the studied individuals with high blood pressure indicates the presence of central hearing disorders. The characteristic feature was that tinnitus was observed only in patients with decreased diastolic pressure «over deep» according to daily blood pressure monitoring. The quality of life of patients with tinnitus was regarded by them as moderate by Tinnitus Handicap Inventory Test. The quality of life of the remaining patients from the two study groups was regarded by them as normal (Figure 1).

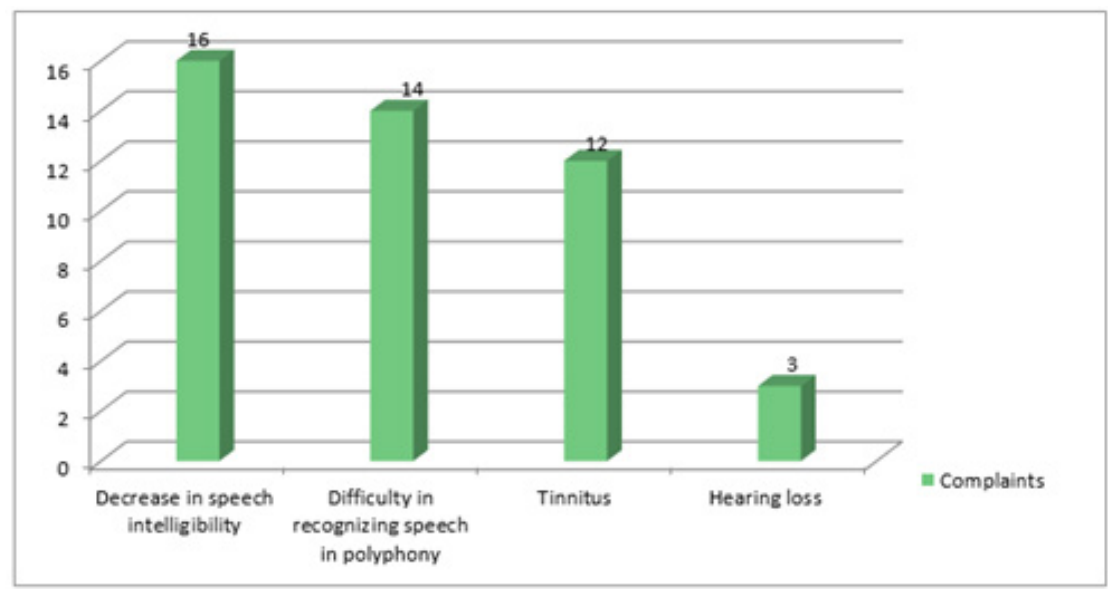

Figure 1: Complaints of patients with arterial hypertension.

Tympanogram type A was registered in all the patients in two groups $(\mathrm{N}=40)$ with bilateral acoustic reflexes. Pure Tone Audiometry showed no significant difference in the change of the hearing thresholds in two groups of patients and all patients from both groups had normal hearing thresholds. High-frequency audiometry showed some changes only in $1 / 3$ of the studied first group ( $\mathrm{N}=7$ ). No statistically significant difference was observed between the both groups with and without arterial hypertension in either DPOAE or TEOAE. All patients successfully passed the test. But the arterial hypertension group showed significantly lower results at 1501, $2002 \mathrm{~Hz}$ frequencies by the distortionproduct otoacoustic emissions. It was significantly revealed an elongation of the interval III-V $(t \geq 0,95)$ with an increase in the amplitude and an increase in the latency of the wave $V(t \geq 0,93)$ in the group with arterial hypertension (Figure 2). Taking into account the complaints of patients of the hypertension group to reduce speech intelligibility at normal hearing thresholds, overthreshold speech tests were conducted. Word Recognition Test, 
Rapidly Alternating Speech Perception Test, Dichotic Digits Test were performed. Speech intelligibility was $80 \pm 5 \%(t \geq 0,95)$ with an extremely low percentage of passing digital dichotic tests$5 \%$ in patients of the first group. Rapidly Alternating Speech
Perception Test values approached the norm in the majority of patients studied from the two groups. Word Recognition Test and Dichotic Digits Test were normal in patients of the second group (Figure 3 ).

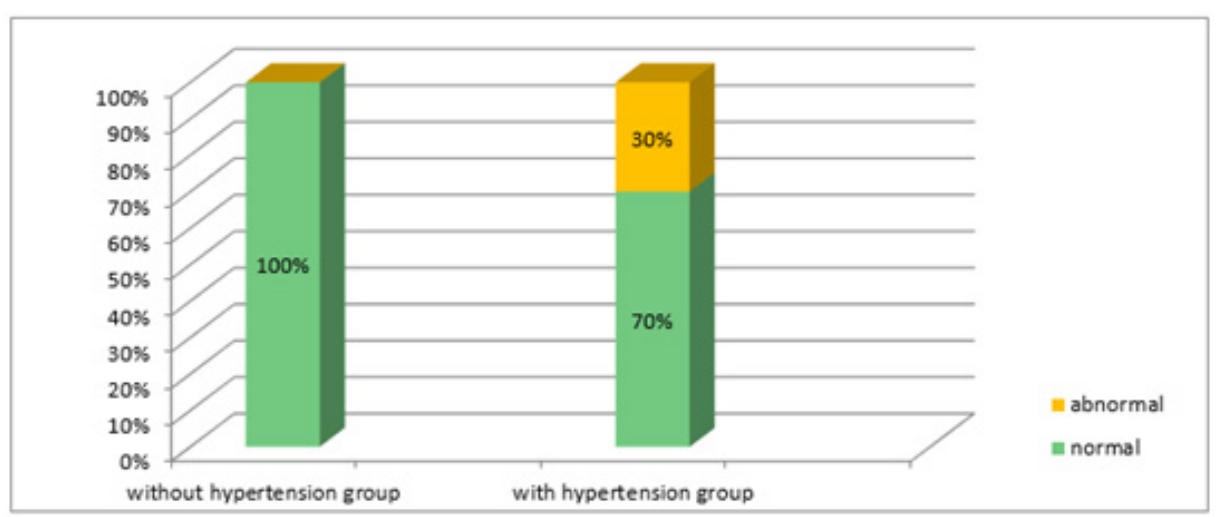

Figure 2: Changes in High-Frequency Audiometry in two groups.

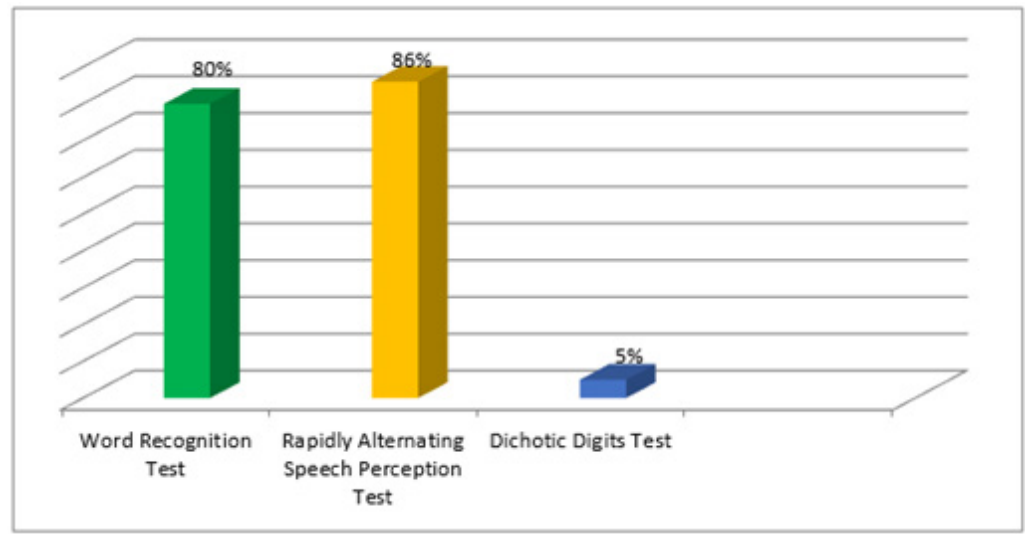

Figure 3: Speech intelligibility in the patients of hypertension group.

\section{Discussion}

In this study, we established that patients with Arterial Hypertension had central and peripheral disorders of hearing organ. The diagnostics of hearing impairment in patients with Arterial hypertension should include in addition to standard battery tests and above-threshold speech tests. The most sensitive of the above-threshold speech tests is Dichotic Digits Test and can be used in patients with high level of blood pressure. Stabilization of blood pressure with medication and the correction of the standard of living for three months led to a decrease in complaints and increased speech intelligibility. As well as the correction of day and night blood pressure levels contributed to a decrease in the intensity of tinnitus. Patients in the second group passed the entire battery of tests. The results of the studies were consistent with the norm, which corresponded to the age and health status.

\section{Conclusion}

Arterial hypertension is a systemic disease that causes damage to the organ of hearing at the central and peripheral levels. Word Recognition and Dichotic Digits Test should be used for diagnosing hearing impairment in addition to the standard battery tests.

\section{References}

1. Bryan Williams, Giuseppe Mancia, Wilko Spiering (2018) ESC/ESH Guidelines for the management of arterial hypertension. The Task Force for the management of arterial hypertension of the European Society of Cardiology (ESC) and the European Society of Hypertension (ESH)/European Heart Journal 39(33): 3021-3104.

2. Thomopoulos C, Parati G, Zanchetti A (2014) Effects of blood pressure lowering on outcome incidence in hypertension. Overview, meta-analyses, and met regression analyses of randomized trials. J Hypertens 32(12): 2285-2295.

3. O' Donnell MJ, Chin SL, Rangarajan S, Xavier D, Liu L, et al. (2016) INTERSTROKE Investigators. Global and regional effects of potentially modifiable risk factors associated with acute stroke in 32 countries (INTERSTROKE): a case-control study. Lancet 388(10046): 761-775.

4. Yusuf S, Hawken S, Ounpuu S, Dans T, Avezum A, et al. (2004) INTERHEART Study Investigators. Effect of potentially modifiable risk factors associated with myocardial infarction in 52 countries (the INTERHEART study): case-control study. Lancet 364(9438): 937-952. 
5. Rarey KE, Ma YL, Gerhardt KJ, Fregly MJ, Garg LC, et al. (1996) Correlative evidence of hypertension and altered cochlear micro homeostasis: electrophysiological changes in the spontaneously hypertensive rat. Hear Res 102(1-2): 63-69.

6. Maria Fernanda Capoani Garcia Mondelli, Andréa Cintra Lopes (2009) Relation between Arterial Hypertension and Hearing Loss. Intl Arch Otorhinolaryngol 13(1): 63-68.
7. Przewoźny T, Gójska-Grymajło A, Kwarciany M, Graff B, Szmuda T, et al. (2016) Hypertension is associated with dysfunction of both peripheral and central auditory system. J Hypertens 34(4): 736-44.

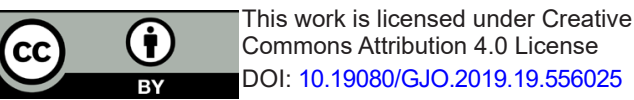

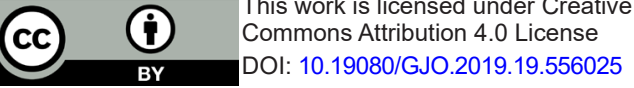

Your next submission with Juniper Publishers will reach you the below assets

- Quality Editorial service

- Swift Peer Review

- Reprints availability

- E-prints Service

- Manuscript Podcast for convenient understanding

- Global attainment for your research

- Manuscript accessibility in different formats ( Pdf, E-pub, Full Text, Audio)

- Unceasing customer service

Track the below URL for one-step submission https://juniperpublishers.com/online-submission.php 